\title{
A Swedish comment on 'review: the availability of life-cycle studies in Sweden'
}

\author{
Greg Peters ${ }^{1}\left(\mathbb{D} \cdot\right.$ Robin Harder $^{1} \cdot$ Rickard Arvidsson $^{1} \cdot$ Henrikke Baumann $^{1} \cdot$ Anna Björklund $^{2} \cdot$ Mélanie Despeisse $^{3}$. \\ Tomas Ekvall $^{1}$ - Niclas Ericsson ${ }^{4}$ - Göran Finnveden ${ }^{2}$ • Torun Hammar ${ }^{4}$ - Matty Janssen ${ }^{1} \cdot$ Carl Karheiding $^{5}$. \\ Hanna Karlsson ${ }^{4} \cdot$ Maria Ljunggren Söderman $^{1} \cdot$ Magdalena Svanström $^{1} \cdot$ Anne-Marie Tillman ${ }^{1} \cdot$ Holger Wallbaum $^{6}$
}

Received: 27 February 2019 / Accepted: 4 March 2019 / Published online: 18 March 2019

(C) The Author(s) 2019

Keywords Bibliographic studies $\cdot$ Peer-review $\cdot$ Google $\cdot$ Scopus $\cdot$ Academic publication $\cdot$ GRI

The article entitled 'Review: the availability of life-cycle studies in Sweden' by Croft and colleagues (January 2019, volume 24, issue 1, pages 6-11) has puzzled many researchers in Sweden. The stated purpose of the article is to review the availability of water and carbon footprinting studies and life-cycle assessment (LCA) studies in Sweden. Despite its title and purpose suggesting otherwise, the article appears to be about the accessibility of lifecycle case studies from Sweden in South Africa. In other words, the article considered documents that can be found and accessed online (either freely or behind a paywall through which most university academics can pass) by researchers based in South Africa, without asking a Swede. It included some academic articles, company reports, and student theses published between the years 1995 and 2015, as found through searches on Google and Google Scholar as well as the scientific databases ScienceDirect, Scopus and Wiley Online Library. The article furthermore included corporate sustainability reports for 2016 indexed by the

Responsible editor: Mary Ann Curran

Greg Peters

petersg@ chalmers.se

1 Environmental Systems Analysis, Chalmers University of Technology, 41296 Gothenburg, Sweden

2 Sustainable Development, Environmental Science and Engineering, Royal Institute of Technology, 10044 Stockholm, Sweden

3 Production Systems, Chalmers University of Technology, 41296 Gothenburg, Sweden

4 Energy and Technology, Swedish University of Agricultural Sciences, Box 7032, 75007 Uppsala, Sweden

5 Swedish Life Cycle Center, Chalmers University of Technology, 41296 Gothenburg, Sweden

6 Building Technology, Chalmers University of Technology, 41296 Gothenburg, Sweden
Global Reporting Initiative. It is problematic that the article claims to be a review in the title and text, but is presented by the journal as a commentary. We believe that the article's method is unclear and that its title and results are misleading.

Besides their assessment of GRI reports, the authors of the article found only 12 academic papers, 10 academic theses, 8 company reports, and 1 presentation. This result significantly underestimates the actual production and availability of Swedish LCA case studies. We tried reproducing the searches mentioned in the article (here referred to as search strategy ' $A$ '), a process made difficult because of the lack of detailed explanation as to how the search terms were used. First, the stated inclusion criterion (that the document features quantitative data) was unclear. Since neither the word 'inventory' nor LCI appear in the article, we took this to mean case studies that report life-cycle inventory or life-cycle impact assessment results. We culled documents about method development, methods comparison with hypothetical cases, and the uptake of LCA in industry. By applying this strict interpretation of the authors' search strategy, only asking for 'life-cycle assessment' or 'carbon footprint' or 'water footprint', and 'Sweden' in the document title (note that for Google the search was not limited to the document title), we found around twice the number of documents (61 instead of 31 , search strategy called 'B1'). But this is still a very narrow search. By adding 'Swedish' in addition to just 'Sweden' and the possibility of the abbreviation 'LCA', we found an additional 16 studies (search strategy 'B2'). Asking ScienceDirect and Scopus for documents having 'life-cycle assessment' or 'LCA' or 'carbon footprint' or 'water footprint' in the title, in combination with the document having both an author affiliated with a Swedish organisation and 'Sweden' or 'Swedish' in the abstract or keywords (as an alternative to the title), added a further 29 studies to the number of documents for the period of interest (search strategy 'B3'). Based on this search, Croft et al. (2019) missed more than two thirds of the relevant documents that could have been 
Table 1 Results of our attempt to replicate and slightly extend the search performed by Croft and colleagues

\begin{tabular}{|c|c|c|c|c|c|}
\hline Search strategy & Description & Life-cycle assessment & Carbon footprint & Water footprint & Total life-cycle studies \\
\hline $\mathrm{A}$ & Croft and colleagues & 13 & 12 & 6 & 31 \\
\hline $\mathrm{B} 1$ & Our search strategy 1 & 34 & 20 & 7 & 61 \\
\hline $\mathrm{A} \cap \mathrm{B} 1$ & Overlap of A and B1 & 11 & 8 & 6 & 25 \\
\hline B2 & Our search strategy 2 & +14 & +2 & +0 & +16 \\
\hline $\mathrm{B} 1+\mathrm{B} 2$ & Subtotal & 48 & 22 & 7 & 77 \\
\hline B3 & Our search strategy 3 & +26 & +3 & +0 & +29 \\
\hline $\mathrm{B} 1+\mathrm{B} 2+\mathrm{B} 3$ & Total & 74 & 25 & 7 & 106 \\
\hline
\end{tabular}

found by a slightly more complete, yet simple strategy. Table 1 summarises these results.

Another point to make is that not every relevant study uses the terms 'life-cycle assessment', 'LCA', 'carbon footprint', or 'water footprint' (let alone 'Sweden' or 'Swedish') in the title. Many of us who regularly publish studies of the sort are not systematically using those terms in the title, instead placing them in the abstract and keywords. By searching more generously for 'lifecycle assessment' or 'LCA' or 'carbon footprint' or 'water footprint' and 'Sweden' or 'Swedish', not just in the title but also in the abstract and keywords, the number of hits in just the Scopus database is raised from 35 to 272 for the chosen period. This suggests Croft et al. (2019) have underestimated Swedish production of relevant academic papers by a factor of eight.

Some of the underestimation may also be connected with excessive trust in Google. Only ten theses are identified by Croft et al. (2019). However, master's degree theses are typically written in English at Swedish universities and are freely available on the Internet. As an example, for the time period in question, Chalmers University of Technology provides the full text of 57 such theses on LCA or carbon footprints in English, online in a central repository (Chalmers 2019a). This is in addition to the 27 doctoral theses on LCA or carbon footprints listed in the research database (Chalmers 2019b), making a total of 84 theses. Chalmers is only one of the universities producing LCAs in Sweden, which suggests the data in Croft et al. (2019) probably underestimates thesis production by an order of magnitude. In a review that goes beyond what the average global citizen can find on Google, to also use academic search tools, one would expect sources like these to be included. We are disappointed by what Google finds and the relative invisibility of potentially important sources for an article like this, for example the CPM and EPD databases (CPM 2019; EPD 2019). But Internet users in different countries or even different users in one country will always get different search results from Google 'thanks' to the search-optimising influence of their own previous search histories; therefore, Google may be a fundamentally unreliable source for a paper like Croft et al. (2019). On the other hand, these additional data sources will be apparent to anyone doing an LCA or a review of LCAs who asks for tips from a Swedish academic active in this field.
So there is a general problem with the article, which is the relationship between its aims and scope. The inclusion of academic literature obtainable by subscription within the scope, not just open access publications, seems to be at odds with the aim of evaluating the general accessibility of data. It suggests instead a broader scope, of assessing the relative rate of production of LCA in various countries. (Authors of Croft et al. (2019) have recently published similar articles on seven other countries.) However, no such comparative analysis is made and in any case, since the search process was so limited, the data is too incomplete to allow this type of conclusion. Rather than being a review of the available data, the article lists a tiny sample of the many Swedish LCAs available from the included sources, and provides some descriptive statistics and comments on this particular sample. We encourage authors to seek peer review and input from a relevant Swede if they wish to broaden and deepen this analysis of Swedish LCA production in the future. We are available for this!

Open Access This article is distributed under the terms of the Creative Commons Attribution 4.0 International License (http:// creativecommons.org/licenses/by/4.0/), which permits unrestricted use, distribution, and reproduction in any medium, provided you give appropriate credit to the original author(s) and the source, provide a link to the Creative Commons license, and indicate if changes were made.

\section{References}

Chalmers (2019a) Chalmers Publication Library. https://publications.lib. chalmers.se (accessed February 2019)

Chalmers (2019b) Chalmers Publication Library. https://research.chalmers.se/ en/organization/?tab=publications (accessed February 2019)

CPM (2019) The CPM LCA Database. https://www.lifecyclecenter.se/ projects/cpm-lca-database/ (accessed February 2019)

Croft J, Engelbrecht S, Ladenika AO, MacGregor OS, Maepa M, Bodunrin MO, Burman NW, Goga T, Harding KG (2019) Review: the availability of life-cycle studies in Sweden. Int J Life Cycle Assess 24(1):6-11

EPD (2019) The International EPD System. https://www.environdec. com/EPD-Search/ (accessed February 2019)

Publisher's note Springer Nature remains neutral with regard to jurisdictional claims in published maps and institutional affiliations. 